\title{
ETHNO-PSYCHOLOGICAL ARCHETYPES: UNCHANGEABLE CODES OF THE HISTORY
}

Narman Godjaturk ${ }^{1}$

\begin{abstract}
The internal mechanism of mythical subjects' self-organization resuscitates the folklore and gives life to it at any time. The folklore becomes active only in a person's life. Particular
\end{abstract} people renew forms existing for centuries on the improvisation basis. Thus one can get rid of monotony and a tradition gets a new breath in the performance of each person as well. The tradition is kept, but expressed by a new rhythm and breath. And it shows that myths always live and go through centuries in a new improvisation. Elements of mythical thinking, as archaeological types, always become the center of the researchers' attention. But there are still such problems in this area, so that are of scientific interest. There are issues among them that have a direct appeal to the philosophical thinking. The observation of striking similarities among myths of the world people is of this kind. These are plot similarities. Even the mythical plots of nations located in a remote geography quite far from one another contain elements and images similar to each other. In Turkish provinces everybody knows the Khizir's Spirit as a cradle song. It is the symbol of the Holiness from its original date. Khizir- a thousand year old Turk fondles his love by the language of the lullaby and bayaties.He has made a tale of his Memory and set up a great deal of saga for himself. In this case the evaluation of mythological plots always maintains its topicality as one of the important terms.

Keywords: amyth, archetypes, a plot, folklore, mythical thinking, Khizir, a human, time, a memory, a tradition, history.

\section{Introduction}

In folklore studies one of the two explanatory versions of nation's mythical plots connected with the possession of similar elements and characters is called the historical school.

\footnotetext{
${ }^{1}$ Assistant Professor, Baku State University, Faculty of Social sciences and psychology.Email: nqocaturk@mail.ru.
} 
It appeared in the first half of the $19^{\text {th }}$ century. According to school supporters the similarity reasons in mythical plots are the same with the grammatical and lexical reasons of languages. This approach is based on a common ethnicity axiom. The ethnic similarity provides the similarity in mythical plots as well. Like the language, mythical ideas are conservative too. It is transmitted orally from one generation to the other.

People's migration, marriage relationships, wars to capture lands and other communication types provide a settlement of an ethnic group in different sections to spread people over the planet. Despite differences in shape this has led to the similarity between the myths with motive and picturesqueness. It should be noted that a lot of Western researchers emphasize Turkic tribes' stimulating role in people's “Great Stream” process. For example, K. Jaspers (Jaspers, K. 1991: 50-75) and J. Modelskey (Medelski, G. 2005: 126-128) can be noted. It is true; K. Jaspers looks significant and malicious. But he also confessed that there were rigorous updates in cultural relations with the people's spreading around the world from Asia. These nations contributed to the history of intercultural communication going to Europe on a horseback.

Saying the wrong historical names and people, K. Jaspers had to adopt, in a roundabout way, the role of Turkish people in spreading ancient cultural elements all over the world. J. Modelskey is in a more concrete position than K. Jaspers. He confesses that the Turkish passionate character stands on the bases of Italian renaissance and the so called "Chinese Renaissance" event by Jack Jerne (he uses "Mongolian Empire"instead of "Turk" expression). J. Modelskey writes:“... but only in reality the Chinese experience was brought over the Italian foundation just thanks to the Mongols Empire. Today they are also the carriers of perceived effects". (Medelski, G. 2005: 126-127).

J. Modelskey estimates this mission as an endeavor of world power creation; i.e. he talks about the historical mission like a dissemination of Turkish cultural elements. There is a need for scientific explanation of Universal Invariants existence. Because this issue doesn't assume scientific-theoretical meaning only, it also has a practical 
importance. From the same point of view another approach should be emphasized too. This approach is based on interethnic contacts. It is called "diffusion" in the scientific literature (see: Bremen, K. 1972, Golosovker, Y.E. 1987, Meletinsky, E.M. 2001, Neklyudov, S. Y. 2004).

"Diffusive" approach is based on an explanation of transcultural plots' movement and their dissemination on a wide geographical area. But despite certain advantages, this approach cannot explain the similarity reasons either, among mythical plots of people with no cultural relations (for example, reasons for plot similarities between Oceania and mainland myths-N.G.). In this regard, the facts brought by S.M. Wilson-an anthropologist, evoke interest. $\mathrm{He}$ describes the possession of similar structures in making up a social life of people living in different parts of the world like this:'If we compare Teotihuacan (the oldest city in Latin America) or Chan-Chan (a city in the Far East) with Uric (Sumerians main city) or Uri we'll find a strong similarity. Cities are divided into functional areas; one can find ceremony, commercial and residential areas there.
The latter is very similar in terms of size and functional organization of space. A resident of one of these cities would immediately understand the other's structural base" (Wilson, S. M. 2003: 140). Having askedthe question where these manifestations get their source and considered the various versions, S.M. Wilson notes that there is not a satisfactory answer and links it to the factor of "uncertainty". At the same time, he emphasizes a need to talk about possible idea of the "manifestation of some internal and general quality" (Wilson, S. M. 2003: 141). Of course, as an anthropologist, S.M. Wilson has a concrete way of thinking, but somehow this motive is interesting- as an anthropologist he puts the issue of "internal qualities" which is common to all mankind.

And finally, the problem is connected with the human factor; i.e. the reason of similarities in lifestyle of people living in different parts of the planet and never being in contact with one another, generally is connected with being a man. There is some common program for a human life and as a whole, with certain difference it is observed anywhere in the world. From time 


\section{Periódico do Núcleo de Estudos e Pesquisas sobre Gênero e Direito \\ Centro de Ciências Jurídicas - Universidade Federal da Paraíba \\ V. 8 - No 04 - Ano 2019 - Special Edition}

ISSN | 2179-7137 | http://periodicos.ufpb.br/ojs2/index.php/ged/index

immemorial man's life consists of different variations of reaction to existing topics-family ties, getting food, having culture, protection from external threads, explaining the world, updating the basic emotions and other common themes.

Being based on these factors the similarities are called "typological". A number of researchers are cautious about it. For example, S.Y. Neklyudov notes that when similarities are found in the texts, we, first, take into account possibilities of intercultural relations, genetic commonality and only then we pay attention to the typological generality (Neklyudov, S. Y. 2004). We are talking about the differences observed in the researcher's approach level; i.e. another researcher can go towards historical and genetic analogues beginning from typological similarities. If the typical approach can explain the similarities between myths, then it can't explain aptly the differences observed between contents of myths.

It must be stressed; each of the three approaches approves that remaining of mythical plots in people's memory for ever, though it changes in some respect, as a matter of fact, remains unchanged and passes from language to language.The issue of keeping the mythical plots in people's memories is the key factor of inferring in a universal level. This factor can play a key role in understanding the philosophy of the connections between the tradition and modernization which manifests itself constantly in the historical evolution. The qualities like conservatism of folklore tradition, the author's lack of creativity, constant availability of "public censorship", rigorous waiting of canons are taken as the starting point for all of the concepts.

Only the typological approach brings the issue of plots' creation to spotlight. The creation of plots is considered as a random result of creative clarifying. One of the main features of folklore is associated with the peculiarity of the cultural information storing method.Folklore is transmitted orally. This is a very serious impact on the content of culture. The storing orally transmitted tradition elements, their welfare, socialization, evolution and influence on different areas of human life obtain a private character. Actuallythe problem is connected with a dynamics of mythical ideas, dialectical unity between 


\section{Periódico do Núcleo de Estudos e Pesquisas sobre Gênero e Direito Centro de Ciências Jurídicas - Universidade Federal da Paraíba V. 8 - No 04 - Ano 2019 - Special Edition ISSN | 2179-7137 | http://periodicos.ufpb.br/ojs2/index.php/ged/index}

keeping itself in the frame of time and social renewal.

For example, the history memory has been written by the shamans. Therefore the shamans became known as chronicle authors as well. Father Qorquthad majority of qualities connected with the shamans.At the same time Father Qorqut was the main carrier of Khizir's features.Father Qorqut was regarded as a myth that looked out from pinnacle of Khizir's wisdom and emitted light upon the earth from Khizir's world. Generalizing "Oghuz letters"- all Turkish memory connected with Qorqutworld, such a conclusion can be drawn that it has always been available anywhere. Turning over the pages of Oghuz memory golden pages introduce us Father Gorgut in different cutting out. Information about Father Gorgut is provided in the image of either chief shaman, a miracle worker or as Khakana country ruler and guider (Gojaturk, N. 2014: 72).

First of all, folk-lore tradition exists in view of the general outlook. Folklore tradition is also heard so much in the frame of memory capabilities of each tradition carrier. It creates a certain degree of unsystematic character. That knowledge became active in a word, behavior and appearance. At the activation moment, in the mental representation area, a transformation of the content into the text occurs. So the researcher doesn't have to deal with the tradition, but its "product". This moment draws attention to a very important refinement-tradition memory is actually connected with the ability to keep in mind and actualize what he hears. It is necessary to pay attention to this moment to generalize the tradition memory and imagine it on the level of "people's memory".

As an example it is possible to bring to view the memory connected with Turk Khizir holiness. It doesn't matter which path of religion the Turks worship, which temple they set foot on, they have never forgotten Khizir's glory. The Turks saw the living as well as energetic spirit and felt it close. The Turks used to say my God is in the heaven, my Khizir is on the earth. They convey their love and wishes to the gates of God by Khizir. And he sat on a white horse's croup and rode to the homeless.He found the way out for the grief of distressed people.He gave to drink in the goblet and kindled the fire in 
loving hearts. When homeland was pressed, he came for help.

So, Turk kept Khizir in memory like that. He regarded himself descending from Khizir. When fertility came to the land, no matter which hamlet they set up ceremonies in and danced "Yally"; they thought all this abundance come from Khizir's hearth. As a lot of saints, they wrote a great deal of sagas and books on behalf of Khizir. Each penholder has introduced this saint as the lineage carrier and belief road passenger. All of these come due to love for the glory of Khizir's spirit. In hamlet sayings Khizir was called by the three types of names: Khidir Nabi (Khizir Ilyas), Khidir Ellaz, and Khidir Zinda.

Our memory storage: tales and sagas are completely connected with Khizir's name. The tales are the product of our new-born child products and childhood, but sagas are of elderly period. Therefore we have presented Khizir as the guy on a white horse in tales, and as dressed in white, whitehaired and illuminating old man in our sagas. According to the sources the almond-shaped pattern holiness which is connected withKhizir in our storage memory, accomplishes a mission of our ancestors' cosmetic thoughts carrier. In ancient people's meditation water, plants, mountains and other assets were considered as sacred and beginning of life. Therefore almond-shaped pattern is the continuation of the generation and the symbol of growth. Presenting almond-shaped pattern to the lover in our sagas and tales begins with giving to drink love sherbet on behalf of Khizir-an old and wise man.Generally, the investigation of folk-lore samples shows that almond-shaped pattern is not given to everyone. Almond-shaped pattern is peculiar only to selected men. These selected men gain for themselves, by almond-shaped pattern, several individual features that don't belong to anyone. The almond-shaped pattern main composition of love epics has always played an important role in saga creativity. According to the love epics, the lover which is given the almondshaped pattern differs by his courage and honesty (see: Gojaturk, N. 2013).

Bringing the sample of mythical Khizir's image which is Turk's memory storage, it is necessary to run over the role of "people's memory" in sociocultural life of community just from this angle; because a leading role of 


\section{Periódico do Núcleo de Estudos e Pesquisas sobre Gênero e Direito Centro de Ciências Jurídicas - Universidade Federal da Paraíba V. 8 - No 04 - Ano 2019 - Special Edition ISSN | 2179-7137 | http://periodicos.ufpb.br/ojs2/index.php/ged/index}

human memory in the tradition activates complex

philosophicaland methodological aspects.

It should be necessary to give, philosophically, the priority to two features of human memory. The first, the memory owner keeps in mind the highlights and throws away others. The second, a man always remembers easy items. He doesn't pay attention to complex and dark details. And this, itself, brings to attention either positive or negative element. For example, tradition elements that are regarded complex and insignificant ones by anybody may solve the fate of an entire nation. These two issues, together, focus attention on the protection of national memory, which aspects to give the priority to, in historical stages, ability to update national memory in social life (this issue is related to the training and education)and method to motivate the community against foreign threats (here an ideology, political, economic and cultural activities, changes in the degree of social consciousness and etc. are important). Another important point is connected with what is related to the desire of a man to save. As a whole, the same thing is a major scientific problem.
Thoughts on it create a need to look at the conception of "valuable information" (H. Haken, D. Chernyayevsky and others) under a new angle (see: Kastler, G. 1967: 11-20 and Khaken, G. 1999: 11-25).

The information "price" depends on selection and generation (self emergence, spontaneous formation) factors. At any specific point the selection of information is related to the information resources that a man has so far and proposed purpose. There two points which define either the information is valuable or not, actually, determine the direction of media evolution. It should be noted that the characteristic as the picking process of one of several and equal variants of information is coherent with the definition of Henry Kastler. According to that definition the information is a selection of one of several, possible and equal options by chance or keeping in memory. There are several views on information to be valuable as part of this approach. The positions of R.L. Stratonovich (Stretonovich, R.L. 1975), N. M. Bongard (Bongard, M. M. 1967), A. A. Kharkevich (Kharkevich, A. A. 1960) and V. I. Korogodin (Korogodin, 


\section{Periódico do Núcleo de Estudos e Pesquisas sobre Gênero e Direito Centro de Ciências Jurídicas - Universidade Federal da Paraíba V. 8 - No 04 - Ano 2019 - Special Edition ISSN | 2179-7137 | http://periodicos.ufpb.br/ojs2/index.php/ged/index}

V.I. 1991) can be shown. Despite the differences between them, all are combined by one opportunity- the price of information is connected with the relation between purpose and the information in the memory. This relation gets concrete mechanism by the selection procedure. So the information value depends on the capacity of memory, selection and information resources for all approaches. In the modern theory of dynamic information the same feature is one of the central factors. But in the framework of our approach it is of a new content. Because we don't have a personal issue, but of collective reality and national level one, and in this case we look at a unity among memory, selection and information resources. For this matter we focus on the reception and acceptance generation (self creation) aspects of information. The first case in the formation of information on the basis of information received from outside. It is staked into new information area regardless of a man's previous information provision. Let's remember moments of coercion and influence from abroad. In the second case- generation is human's choices by chance, without outside influence. With this option, information recourses available to people are of great importance (Chernovtsy, D. S. 2004: 1920). However, a self-regulation mechanism of human memory plays a key role for both options.

If forgetfulness eliminates limitations which arise as a result of previous observations which arise as a result of previous observations on the one hand, on the other hand, it gives a boost to archeological types to direct people psychologically and practically from time to time. A man, forgetting something in his private practice, doesn't lose direction, but the forgetfulness can lead to non-restored direction and ultimate destruction. Moreover, it can happen at the community level. When folk-lore layer undergoes an external aggression, is fully opened to external influence and leaves itself, the people memory decays and consequently the community is annihilated. There are a lot of examples for this in history. This method is widely used in today's world of information war.

Moral tradition plays a serious, stimulating and organizing role in all spheres of human society. But hot and significantly autonomous political 
activity creates a lot of problems. At the same time, figuratively speaking, moral factors implement the "backstage" function. They are not directly felt in the materialized form, for they determine the idea at social life organization and philosophy. Opportunities behind the content of the performance may not cause anxiety for social-political factors at that moment. Here we must not forget man's characteristics of hiding the truth for his own benefits. History proves that political factors always benefit from that. In other words, those who understand moral and spiritual qualities carried by the people for centuries have not been frankly using them at their work. In all cases,an approach to the so called event "unwritten laws of life" by modern and scientific knowledge prism can bring in new exciting ideas.

Ifthe writing is a slavery of ancient thinking based on verbal communication, then, it will be not able to express all details of that thinking. Including information which is always unwritten and transmitted by secret codes will not be reflected there. This finding raises the question of how to understand the role of tradition in the culture of writing and developing civilization. In other words, if the community considers rationality and writing culture as the grounds,approaches mythical imaginations within the primitive level framework, the evolution of this type of society won't be confident and sustainable.

Collective being's memory takes part in the transmission process of either oral or written information. In modern times, it can be available in an interaction between two factors. If sagas may even be factors which are the basis of people memory's oral layer, in modern times the issue of their written transmission is equally important. Precisely, the written transmission is more actual with modern terms.

There issues are connected with analysis of the relationship between language and life as part of the abovementioned philosophical schools. M. Hidegger calls the forms of knowledge and life as an authenticity. In other words, each of them is actualized in an example of individual. But both are of the same basis. In spite of this, M. Fuco says that this basis would not be the same. The language can improve regardless the life form and according to 
the internal demand. We can think of this provision's role in people's memory without accepting it as the absolute truth. The people's memory, actually, can go unchanged through tests of time. Then, in a sense does not depend on a social background. For its carrier, a nonlocalized collective is a spiritual space; it keeps preceding regardless the lack of physical space. Procedural keeping means that the memory, for centuries, does not let the community out of its evolution corridor. In each new historical stage just people's memory determines, ultimately, the form of socio-cultural atmosphere. This is a serious allegation.

The determination of sociocultural atmosphere form by people's memory is principally the confirmation of content assuming as a general form in each concrete situation. The main line of this process is the memory. The main line of this process is the memory. The system memory provides overcoming optimum uncertainties in encounteredsituations throughout its history (see: Lumen, N. 2004). If the system loses memory, it is deprived of the details gained in an experience and ability of active adaptation to the new situation. It does not have any chance to win the same ability again, because the history of the self-generating system is so serious,that each stage has its own role. Habits and qualities that must have been obtained in this stage are not obtained later on. Therefore historical memory system is one of the main conditions of its existence. The existence of people's memory entirely refers to the community existence, because it belongs to the collective reality. The weakness or loss of that memory is always a tragedy. Here, it is necessary to note the role of the individual. In other words, though people's memory belongs toa non-local and common moral field, it always founds its manifestation in concrete individuals. The individual provides entirely systematic socio-cultural atmosphere as its carrier.

\section{Results}

The history is an evolution of folklore and life rules of a mankind. Myth lives in human and gives a life to human by self-organization. This process gives an order creation effect from common level and chaos. Its mechanisms are explained by above mentioned selection and value of information, collective memory 
existence, and unity of information condensation with forgetfulness, reception and working rules of generation. Together with the role of each of them separately, created collective effect determines myths evolution. Transmission mechanisms from individual level to collective oneare the main unity creating factors. Selforganization philosophy is connected with it. Actually, a chaos in the microlevel (relationships between individuals) and an order in the collective level (community-wide observed processes) are its manifestation. When looking at myth on that prism we come across an exciting and dynamic landscape.

\section{Scientific innovation}

Inrecent years, the communication aspect in folklore is being more swelled. Such phenomena like domestic tradition mechanisms, transmission and storage methods of texts are gaining attention. It is interesting that, just so interesting issues raise new questions, even, sometimes shape paradoxical situations. The clarification of mythical plots for1. whether they have or not a quality of self-creation has been tried in this article.
And this issue, in the true meaning of the word, is of fundamental importance for the scientific and philosophical thinking. If mythical plots' self-formation ability is proved, the notions about the world history must be radically changed. An attitude to social and historical time concepts should be changed. The gist of highlights which stand now behind the accruing events may seem a new angle. In history the issue of the role of personalities, states, socio-political and cultural processes can be lighted on under wider angle.

\section{The Importance of Applying}

The experts dealing with mythology, history of philosophy, students of Bachelor's and Master's degree of high school and interbreeding may benefit from this article. The presented article can be used as a text book on the history of mythology and philosophy, manuals and scientific source in preparation of programs.

\section{References:}

Bongard, M. M. (1967). Recognition Problems. Moscow. Science. 
Bremen, K. (1972). Logic of Narrative

Possibilities. // "Semiotics and

Artmeter”. Moscow. Peace.

Gojaturk, N. (2013). Khizir

Aleyhisselam. The Turkish Boy on a

White Horse. Istanbul.

Chernovtsy, D. S. (2004). Synergetic and

Information. (Dynamic Theory of Information) // G.G. Malinetsky $2^{\text {nd }}$ edition, revised and expanded. Moscow. Editorial URSS.

Foucault, M. (1972). The Archeology of Knowledge and the Discourse of Language. New York.

Golosovker, Y.E. (1987). The Logic of the Myth. Moscow. Main Edition of Eastern Literature. Publishing House "Science".

Khaken, G. (1999). Can We Use Synergies in the Human Sciences? "Synergetic and Psychology" Texts. Issue2. "Social Processes". Edited by I. N. Trophimov. Moscow. "YNUS-K”.

Kharkevich, A. A. (1960). About the Value of Information, "Problems of Cybernetics". Issue4, Moscow. Physics and Mathematics Publishing.

Kastler, G. (1967). The Emergence of Biological Organization. Moscow.

Korogodin, V.I. (1991). Information and Lumen, N. (2004). Society as a Social System. Translated from German. / A. Antonovsky. Moscow. Publishing "Logos".

Meletinsky, E.M. (2001). From Myth to Literature. A course of lectures "Theory of Myth and Historical Poetics" Moscow. Russian State University for the Humanities.

Medelski, G. (2005). Evolution of Global Politics. // Political Publishing, №4. c. 124-141. Moscow.

Media Phenomenon. Pushino: A.S.

SSSR. 
Neklyudov, S. Y. (2004). Why Are Tales

the Same ? // Live Old- M.N. (41)

Stretonovich, R.L. (1975). Information

Theory. Moscow. Soviet Radio.

Terker, V. (1983). Symbol and Ritual.

Moscow. (Science).

Wilson, S. M. (2003). Determinism and Uncertainty in the History of States'

Origin. A Man Facing Uncertainty.

Moscow. Computer Research Institute.

Jaspers, K. (1991). The Meaning and

Purpose of History. Translated from

German, Moscow. Political Publishing 